San Jose State University

SJSU ScholarWorks

Master's Projects

Master's Theses and Graduate Research

5-1-1999

\title{
Women's Perception of Provider, Social, and Program Support in an Outpatient Drug Treatment Program
}

Melaine Marie Salmon

San Jose State University

Follow this and additional works at: https://scholarworks.sjsu.edu/etd_projects

Part of the Maternal, Child Health and Neonatal Nursing Commons, Other Nursing Commons, and the Public Health and Community Nursing Commons

\section{Recommended Citation}

Salmon, Melaine Marie, "Women's Perception of Provider, Social, and Program Support in an Outpatient Drug Treatment Program" (1999). Master's Projects. 862.

DOI: https://doi.org/10.31979/etd.cs8y-nb7m

https://scholarworks.sjsu.edu/etd_projects/862

This Master's Project is brought to you for free and open access by the Master's Theses and Graduate Research at SJSU ScholarWorks. It has been accepted for inclusion in Master's Projects by an authorized administrator of SJSU ScholarWorks. For more information, please contact scholarworks@sjsu.edu. 


\section{SAIN JOSE STATE UNIVERSITY \\ SGHOOL OF NURSIMG}

\section{MASTER'S PROGRAM PRONECT OPTION (PLAN B)}

PRQVECT SIGNATURE FORM

STUDENT NAME

SEMESTER ENROLLED

TITLE OF PROJECT
Bridgette M. JosepH / Melaine SAlmon Fall 1996 Women's perception of provider, Social and program support in an outpatient Drug Treatment program

The project and manuscript have been successfully completed and meet the standards of the school of Nursing at San Jose state University. The project demonstrates the application of professional knowledge, clinical expertise, and scholarly thinking. An abstract of the project and two copies of the manuscript are attached.
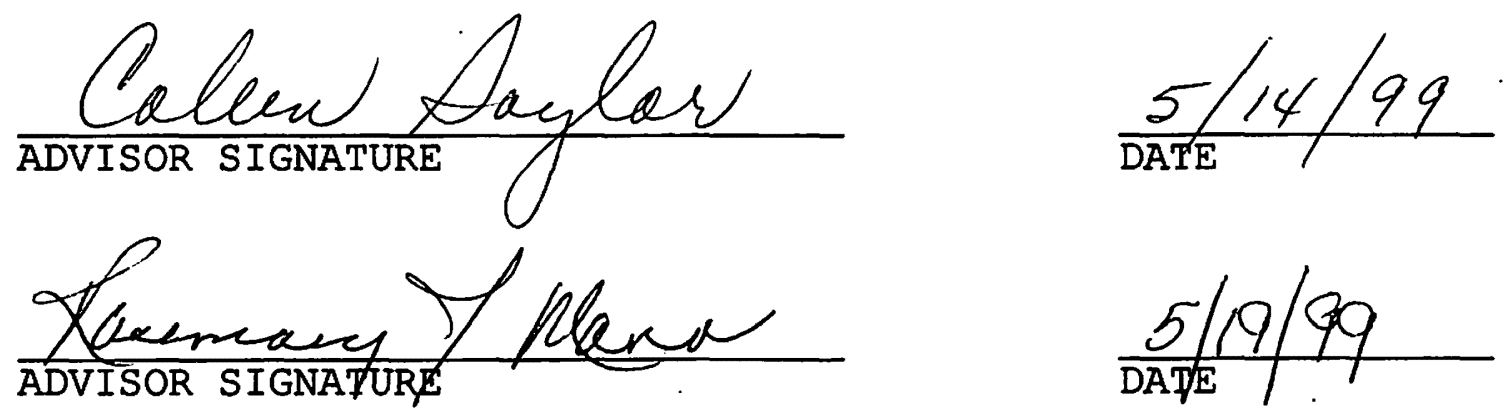

Please submit this form to the Graduate Coordinator. Attach the abstract, two copies of the manuscript, and documentation of submission to the journal. 


\title{
WOMEN'S PERCEPTION OF PROVIDER, SOCIAL, AND PROGRAM SUPPORT IN AN \\ OUTPATIENT DRUG TREATMENT PROGRAM
}

\author{
by \\ Melaine Marie Salmon, B. S. N. , R. N. \\ Bridgette Michelle Joseph, B.S. N. , R. N. \\ Affiliated with Department of Nursing \\ San Jose State University \\ San Jose, CA \\ Acknowledging Coleen Saylor, Ph. D. , R. N. \\ Acknowledging Rosemary J. Mann, R.N. , J. D. , Ph. D.
}

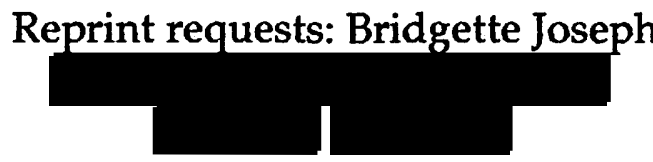

Running Title: Women's Perception of Support

5 key words words for indexing: substance abuse, treatment, social support, outpatient services

Corresponding author: Bridgette Joseph

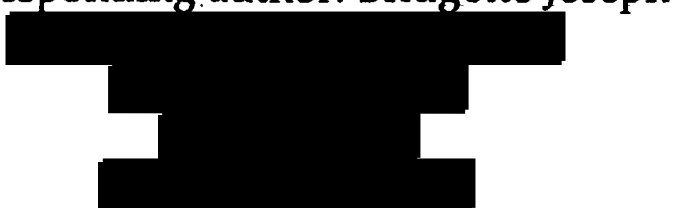


Title: Women's Perception of Provider, Social, and Program Support in an Outpatient Drug Treatment Program

\begin{abstract}
The purpose was to explore perceptions of pregnant and parenting substance abusing women in an outpatient drug treatment program regarding provider and social support. Also identified were aspects of the rehabilitation program perceived by the women as assisting them to maintain abstinence from-substance use. Data were collected through a demographic questionnaire and a tool designed by the authors based on the Social Stress Model of Substance Abuse (Lindenberg, Gendrop, \& Reiskin, 1993) and the literature of social support. The majority of the women were satisfied with their social support from family and friends. Sixty-seven percent of the women felt the support received from medical providers were not adequate. Also, the majority of the women received no information on risks of drug use and pregnancy from their medical providers. The women felt the program helped maintain abstinence by providing education, coping mechanisms, resources, 12 Step programs, and spiritual guidance.
\end{abstract}


Introduction

Data for drug abuse indicators shows that while the reasons are unknown, substance abuse by women during pregnancy continues to increase (National Institute on Drug Abuse, 1995). Therefore, a model for effective treatment is necessary to provide women with appropriate resources to support their recovery process. In addition the importance of social support and social networks for women recovering from substance abuse needs to be explored. Only within the last 15 years has more attention been paid to women's substance abuse. Yet, the literature suggests that substance abusing women have been the target of anger and blame and that continuing neglect of the issue has led to a lack of treatment services (Finkelstein, 1994).

It is estimated nationally that $10-15 \%$ of newborns in inner city communities are exposed to illegal drugs in utero (Center for Substance Abuse Treatment, 1993). This illegal drug exposure and exposure to legal substances, such as alcohol, result in such possible long term effects on the infant as an increased incidence of congenital anomalies, mild neurodysfunction, transient electroencephalogram abnormalities, cerebral infarction and seizures, vascular disruption syndrome, sudden infant death syndrome, or small head circumference (Center for Substance Abuse Treatment, 1993).

Substance abuse among pregnant and parenting women has been an often discussed and studied topic. Most experts agree that polydrug abuse is the most common pattern among pregnant women (Higgins, Clough, \& Wallerstedt, 1996) . Połydrug use in women may result in physical, neurological, and behavioral effects that increase the risk of both immediate and long term problems (Wilkerson, 1997) . Many past studies have focused on the high costs required to treat these drug-exposed infants and sought strategies to decrease those costs. According to Worner and Delgado (1995), the costs for treating alcohol and drug-exposed neonates could approach 5 billion dollars annually. However, attention must also be directed towards the 
substance abusing woman. While there are many drug rehabilitation programs in place, the rate of maternal drug abuse continues to rise (Higgins et al. , 1996).

According to Blume (1992), women are more apt to state that their addiction to alcohol and drugs occurred as a response to severe stressors and to seek help for health and family problems. Yet, information is rarely sought regarding the experience of addiction recovery for pregnant and parenting women from the client's point of view. This information would provide a description of factors that support the woman's efforts to maintain sobriety and also those that act as stressors. This information would increase knowledge about the stress that these substance abusing women experience and suggest different solutions to help decrease that stress. Appropriate interventions would in turn decrease the likelihood of substance abuse again.

The purpose of this study is to explore the perceptions of pregnant and parenting substance abusing women in an outpatient drug rehabilitation program regarding provider support and social support. This study will also identify which aspects of the rehabilitation program are perceived by the women as assisting them in maintaining their abstinence from substance use.

\section{Literature Review}

Alcohol and drug abuse among pregnant and parenting women is a critical issue given the consequences to the mother and the child. Continued research to identify factors that contribute to successful treatment is needed to determine effective treatment approaches.

Aspects included in successful treatment programs are the provision of transportation, housing, child care, and parenting support. Programs should provide coordinated, comprehensive, and family centered care to increase effectiveness. Finkelstein (1994) suggested that effective treatment programs assist the client to develop models for healthy, mutually empowering, and non-destructive relationships.

The relationship between services provided and successful outcomes has been studied. 
One study of pregnant substance abusing women participating in an outpatient drug treatment program examined whether there was an association between abstinence and the level of services provided (Zlotnick, Franchino, St. Clairc, Cox, \& St. John, 1996). The results of this study found that women who were abstinent received more services, group treatment, and job related services. In addition, this study found that women who received family therapy were four times more likely than others to maintain abstinence.

The cffectiveness of treatment interventions in maintaining abstinence from substance use and enhancing compliance with prenatal care for women with cocaine dependency was examined (Elk, Mangus, Rhoades, $\Lambda$ ndres, \& Grabowski, 1998). Twelve women were randomly assigned to an experimental group or a control group. All of the 12 subjects received drug counseling and weekly prenatal visits. The experimental group received a cash allotment for cocaine abstinence and attendance at prenatal visits. 'The results of this study found a high rate of abstinence from cocaine in both groups; $99 \%$ of urine samples were negative. However, the experimental group had higher attendance at prenatal care visits and no adverse perinatal outcomes. Eighty percent of the women in the control group had adverse perinatal outcomes.

Mothers who completed a drug rehabilitation program that provided comprehensive scrvices have identificd helpful aspects of thcir program (Carten, 1996). Using intervicws and reviews of case records, Carten (1996) suggested that the following variables assisted the women with abstinence: (a) frequent home visits, (b) staff outreach, (c) urine testing, (d) positive relationships with staff, (e) staff encouragement and non-judgemental attitudes, (f) non-punitive response to relapse, $(\mathrm{g})$ the team approach to treatment, $(\mathrm{h})$ and engagement of family and significant others in the program which created an extended support system.

Fven with drug treatment, however, many infants are still born with evidence of maternal drug use. One study indicated that $31 \%$ of neonates whose mothers participated in a 
comprehensive drug treatment program during pregnancy still had positive toxicology screens (Jansson, Gazaway, Cullins, Iluggins, \& Folden, 1993). Ilowever, this study did not demonstrate the reasons why women did not maintain abstinenec.

The literature regarding the role of treatment programs for pregnant and parenting substance abusing women suggests that additional information on the needs of this population is necessary. With no clear definition of what constitutes a successful treatment plan, the problem of substance abusc in pregnancy and carly parenting remains a common onc, with potential hazardous outcomes.

Social support was identified as a crucial component in a successful drug treatment program, as it allowed individuals to adapt to stressful life situations. The significant others who provided social support helped the individual concerned to exercise mental resources as fully and effectively as possible, whilc the support recipient utilized that support to cope with the stressful situation. Support persons also provided concrete material help or offered their time (Caplan \& Killilea, 1976). Throughout the addiction recovery process, many stressors are placed upon the substance abusing women, as they go through a major life change. It is important, then, to have social support to help these women as they progress through their recovery. Most people have some sort of network of social support that plays a major role in resolving problematic situations (Tarkka \& Paunonen, 1996). One study found that women in a drug rehabilitation program indicated that health care providers and perinatal educators were perceived as providing some basic social support while caring for and treating chemically dependent women (Higgins et al. , 1996) .

liormal social support groups have also been found to predict improved clinical outcomes and cost savings. Women in an urban hospital based obstetrical clinic were interviewed and referred to drug treatment programs and an on site support group (Svikis et al. , 1998). 
Compliance and attendance at the support groups were monitored and maternal and infant outcome data were obtained from medical records. This study found that a substance abuse support group for pregnant women resulted in more favorable clinical and economic outcomes when compared to women who did not attend the support group. For cxample, birth weights were higher, Apgar scores were higher, and medical costs for the mother and infant were lower.

The nature of the interpersonal and social processes that define addiction recovery was cxamined using grounded theory methodology (Nardi, 1998). After cxamining low income single women enrolled in an outpatient intensive treatment program, Nardi (1998) suggested that women began to form relationships with other group members and provided reciprocal support. In addition, the program staff were viewed as sources of support. Other implications of the study were that health care providers can serve as advocates for women and collaborate with community support and treatment programs.

Substance abusing women reported higher levels of stress than non-substance abusing women. $\Lambda$ study regarding parenting stress and coping behaviors of both substance abusing and non-substance abusing women was conducted by Kelley (1998). The Parenting Stress Index was used and the results indicated that the substance abusing women scored higher than the non-substance abusing women on total stress. The higher scores would suggest that these mothers may have less effective parenting strategies and negative coping behaviors, resulting in more difficult interactions between them and their children (Kelley, 1998). This study suggested that more research was needed to determine ways to support the substance abusing mother to decrease her stress and improve her coping behaviors.

Conceptual Model

This current study utilized the Social Stress Model of Substance Abuse (lindenberg, Gendrop, \& Reiskin, 1993). This is a model that integrates a variety of psychosocial theories 
and models. This model was originally developed to explain the parameters that influence drug use for urban teenagers. It emphasizes individual and family system variables and social networks with attention to social influences of family and pecrs, competence, and coping. The basis of this model is that the likelihood of a person becoming involved in drug use is dependent upon the level of stress and the extent to which it is offset by stress modifiers. The stress that can occur may arise from within the family, the work setting, the school, the peer group, and/or the community. The stress modifiers can be social networks, social competencies, and resources. How people interpret and cope with their stress directly correlates with whether they access resources. $\Lambda$ core part of this model is that individuals are better able to cope with stress if they have positive social networks with their families, co-workers, and peers. Those individuals who do not have positive social networks may begin to utilize drugs to cope with their stress. The drugs will allow them to have a false sense of coping skills, which may lead to increased drug use and then drug abuse as their stress response. This stress response can be immediate or delayed (Rhodes \& Jason, 1990).

Stressors can be grouped into five different categories. The first is a major catastrophic life event such as a car accident or the death of a parent. The second is a life transition such as a marriage, parenting issuc, a divorce, or changing a job or home. 'The third stress catcgory is daily hassles such as frequent arguments with a significant other or parents. The fourth category is enduring life strains, such as dealing with lack of privacy, inadequate housing, or school/work problems. The last stressor category is developmental stresses, such as the pressure to fit in with peers, adhere to norms, or establish a satisfying relationship (Rhodes \& Jason, 1990).

The stress modificrs are also grouped into categorics. The first stress modificr category, social networks, is made up of family and peer relationships. These relationships influence an individual's decision to initiate or escalate drug use, or both. Social networks can help an 
individual to communicate and carry out their values and standards, develop social attachments, and receive support (Rhodes \& Jason, 1990).

The second stress modilier category, social competence, is the innate personal factors such as personality characteristics, decision making, communication, or peer-resistant skills that influence a person's decision to use or not to use drugs. This model suggests that if an individual has a variety of coping skills and the ability to utilize them, they are at a lower risk for drug use. Social competence allows the individual to utilize effective solutions to avoid high risk situations (Rhodes \& Jason, 1990) .

The third stress modifier category is resources within the community such as school, health, and neighborhood services. These resources provide information that may influence behavior directly or indirectly. The model suggests that individuals with little or no community resources are at a greater risk for drug use than those with adequate community resources (Rhodes \& Jason, 1990).

The Social Stress Model of Substance $\Lambda$ buse (Lindenberg et al. , 1993), provides relevant social system concepts with which to view the problem of substance use by the pregnant and parenting women. Rarely is this problem seen as a stress response. Using this model and eliciting the clients' perceptions may provide relevant information for rchabilitation programs.

$$
\text { Methodology }
$$

This study was a qualitative study of pregnant and parenting women enrolled in an outpatient drug rehabilitation program. The purpose of this study was to explore the perceptions of pregnant and parenting substance abusing women in an outpatient drug rehabilitation program regarding provider support and social support. This study also identified which aspects of the rehabilitation program were perceived by the women as assisting them in maintaining their 
abstinence from substance use. The subjects were a convenience sample of 20 women who volunteered to participate in the study. The women were over the age of 18 and had a history of substance abusc. The women also agreed to maintain abstinence from substance usc while enrolled in the treatment program and were monitored weekly with urine toxicology screenings. Participants were recruited through an advertisement posted at the agency. Interviews were held in a private office and lasted approximately one hour.

The setting was an intensive outpatient drug treatment program scrving pregnant and parenting substance abusing women, designed to promote the health and normal development of the children. The program model was to provide a "one stop shopping" approach with a focus on the entire family, implying that all needed services were available on site.

The program was a nine month program that required completion of four levels for successful graduation from the program. Most of the subjects were in level two or above, which indicated maintenance of sobriety for at least two months. The treatment services provided at the agency included child care, transportation to and from the agency, individual counseling with case managers, group counseling covering alcohol and drug education, introduction to the Twelve Steps of recovery, relapse prevention, health education, education in domestic violence, parenting skills, and life skills. In addition, referral for mental health services and intensive casc management for other needs of the women (i.e., housing, childcare, financial assistance, etc. ) were provided. Random urine drug screens were done weekly. The clients of the program were also involved in the planning of their treatment plan.

Human subjects approval was obtained from San Jose State University and the agency Institutional Revicw Board. All information was confidential and subject participation did not affect the treatment program.

Data for this study were collected through the use of semi-structured questionnaires 
during a private interview. Written notes and audiotapes were made. The initial questionnaire collecled demographic data and drug history. The second questionnaire was designed by the rescarchers for collecting data on social support, provider support, and aspects of treatment program perceived as effective in maintaining abstinence.

Analysis included summarizing quantitative variables with descriptive statistics. Responses to the open-ended interview questions were analyzed by separating them into three categorics suggested by the conceptual model and the relevant litcrature: program support, provider support, and social support.

\section{Results}

\section{Demographic Data}

Of the 20 subjects interviewed, the majority were Hispanic $(\mathrm{n}=11,55 \%)$, single $(\mathrm{n}=14$, $70 \%$ ), and uncmployed (n=19, $95 \%$ ) with Aid for lamilics with Dependent Children (Al:DC) as the primary source of income. The average age was 30 , average number of children 3.3 , and average number of pregnancies was 4.9 (Table 1 ).

Of the 20 women interviewed, $60 \%(n=12)$ were referred from the criminal justice system, $20 \%(n=4)$ were referred by social services, $15 \%(n=3)$ were a self-referral, and $5 \%(n=1)$ by a family member. Ninc out of 20 (45\%) reported starting drug use between the ages of 10 and 15. When the women were asked to name their drug of choice, there were 33 responses with 11 of the responses (34\%) identifying methamphetamine as their drug of choice (Table 2).

\section{Program Support}

The first category of analysis of interview responses was program support, which included the women's perceptions regarding what aspects of the treatment program were effective in assisting them to maintain abstinenec. Three themes emerged from the subjects' perspectives about ways in which the drug rehabilitation program provided support to them. 
These perceived aspects of the program were (a) the educational classes, (b) dealing with stress, and (c) various stall roles in the program. To enhance the knowledge about treatment program effectiveness, pregnant and parenting substance abusing women described treatment factors they felt were effective in their recovery.

Educational classes were identified by a majority of the women as effective in helping them to maintain abstinence. Some of the topics mentioned were parenting, education, Twelve Stcp study, relapse prevention, drug education, development of increased self-cstecm, awarencss of social consequences of drug use, and spiritual guidance.

The following are a sample of participants' responses regarding specific classes. The drug education class included instruction in physical, emotional, and psychological effects of drug use. Statements made regarding drug education were, "It helps learning about poisons and toxins and what happens when I put them into my body" and "rcalizing how messed up my life was before finding out I had a disease. ". The Twelve Step Program provided education on the steps of recovery including a spiritual component, which focused on the concept of having a "higher power. "One participant stated, "Working on the first step, remembering self-esteem, remembering that I am a better person when off drug, it's like two different personalities. "

In addition to information from the classes, subjects reported a strong sensc of social support among the participants. They referred to this strong social support as a "sisterhood." Social support from others in the program included the ability to talk without being judged, having others who have similar experiences, shared knowledge, getting inspiration from others, and receiving transportation to meetings. One statement made by a participant regarding how she received inspiration was, "the knowledge of people at the program having their children taken away and seeing their pain."

Negative responses related to the program were very limited during the interviews. 
Some examples of negative responses were, "I felt the program didn't help" and "I felt the discussions were too long and I couldn't relate."

A second theme of program support was learning to deal with stress. Clients shared strategies and coping mechanisms that they perceived as effective. Table 3 lists different categories of dealing with stress derived from the data analysis as reported by the subjects. One of the frequently mentioned ways of dealing with stress was the social support provided by others in the program. This included exposing them to others dealing with similar experiences and obtaining feedback and advice from others. Additional ways in which the program helped the women deal with stress not included in Table 3 are: providing rides to the program, establishing a daily routine,and encouraging them to help others.

The third theme representing mechanisms of program support was staff roles. The subjects described various staff activitics as being important in their recovery. One of the activities was providing resources. Resources most frequently found to be effective by the subjects were referrals for medical and dental care, referrals for the Women, Infants, and Children (WIC) program, provision of transportation, and assistance with social services, legal, and housing information (Table 4) .

Subjects were asked to identify any staff role perecived as supportive. 'The staff roles mentioned by the subjects were counselor, program manager, and parenting teacher. In all, 26 responses were identified, including $62 \%$ who indicated positive counselor was supportive, $12 \%$ indicating program manager support, $23 \%$ indicating staff support, and $4 \%$ who indicating parenting teacher support. Reasons why the staff were supportive included, "she listens and holps solve problems,"; "thcy are always there for you," ; they instill good valucs, "; "they give encouragement/praise,"; "they help with boyfriend problems,"; and "provide a safe environment.". 
Regarding their overall experience with the rehabilitation program, $45 \%(n=9)$ of the participants described it as "greal." $\Lambda$ nother $10 \%$ (n 2) reported that "il" you keep coming to the program and want it, it will work, "while $20 \%(\underline{n}=4)$ felt the program "rcinforecd learning. " Ten percent ( $\underline{n}=2)$ felt that you "learn it [the knowledge] and apply it [skills]" and $15 \%(\underline{n}=3)$ rated the program as "providing good stress and coping skills."

When the participants were questioned as to how the rehabilitation program could provide better support, ninc out of the 20 women thought that nothing different could be done and that someone was at the program to assist with every problem. Four of the twenty women believed that the rehabilitation program could be more supportive by providing better child care. Other responses of support that could be added included providing advocacy for housing, feeding the clients lunch, and offering math as an educational class.

\section{Social Support}

Three themes were identified related to social support. The first theme was that the women were not satisfied with the support from family and friends when they were using, but much more satisfied with the support they received once they were in recovery. Another theme was the lack of faith from some family and friends that the women would be successful in recovery, even though they werc in a rehabilitation program. 'The last theme was the importance of social support while they were in recovery.

The majority ( $\underline{n}-15,75 \%)$ of the women reported being satisfied with their social support from family and friends, although fewer $(\mathrm{n}=12,60 \%)$ reported that their social support was adequate. An example of an adequate support was, "My sister helps, she listens, takes me places, and has becn clean and sober for 8 years." . Responses related to inadequate social support were, "[T was] not satisfied with support during using, but once in recovery, satisfied with support, "; "I felt that others thought that I wasn't going to be able to do it [recovery], "; 
"I can't ask anyone for support, it is painful, since I am struggling, and there is no one to help," ; and "My family support is not adequate. Only my sister is supportive; my brother doesn't talk to me; and my mother is not supportive. She is waiting for me to fail." .

Subjects reported parents primarily provided financial support. Mothers were more frequently mentioned than fathers. Others that the women relied upon financially were significant others, other family members, and one woman felt that she had no one to rely on financially.

The women received most of their emotional support from parents or siblings. Others that the women relied upon emotionally were their friends and other family members. For problem solving, the majority of the women relied on their counselor, sponsor, or mother. Others that the women relied upon for solving problems were other family members and friends.

In response to the question asking who were the people they could count on, the women identified their mother and/or father and other people in the program. Some of the women believed that they could also count on a sober living environment, God, and church members. Provider Support

The third category was support provided by the health care provider. These responses are divided into perinatal educator, physician/nurse practitioner, and staff nurses. Overall, women reported that the providers did not give information regarding drug use in pregnancy and possible risk factors associated with drug use and pregnancy. Although the majority of the women said that they were satisfied with the provider, they still perceived that the support was not adequate and that providers could have been more effective (Table 5).

The perinatal educator was usually a registered nurse in an outpatient setting. Of those who had a perinatal educator, $50 \%$ stated that they received good support: "The perinatal educator let you know she was there and could help with whatever she can. "One of the women shared, "I did not trust myself to share information about my drug use." Sixty four percent 
indicated that the support received from the perinatal educator was adequate (Table 5).

The kind of support that the women received varied from, $35 \%$ receiving brochures/pamphlets, to $8 \%$ receiving information on parenting, and $8 \%$ receiving information regarding effects of drug use on baby/delivery risks. Some subjects reported receiving no support or information since the perinatal educator was aware of their enrollment in a drug rehabilitation program, or was not aware of their drug use during their pregnancy. One woman responded that the perinatal educator, "talked about defects for my baby, the risk of delivering ahead of time, consequences of a positive toxicology screen on my baby. "

Concerning physician, nurse practitioner, and nurse support of the 18 women who responded, $77 \%$ of the women received medical care from a physician and $23 \%$ from a nurse practitioner. Of those, $45 \%$ stated that they received provider support, "The NP provided great medical care, she did an assessment on me and the baby. ". The others replied that they did not receive provider support, "The MD was not supportive and I did not feel comfortable asking questions, and the $\mathrm{MD}$ just said, if nothing is wrong, okay. ".

The majority of the women stated that they received no information on drug use and pregnancy and on tests and screening. One statement mentioned was, "I received no information regarding risks of drug use during pregnancy because the doctor wasn't aware I was using while pregnant. "Of the 18 women who received provider support, $91 \%$ believed that they could trust their provider. Statements that the women made about trusting their provider were, "The doctor gave good medical care for the baby and that was it" and "The doctor knew that I used during a previous pregnancy and always told me that if I was using, I could tell him. ”

In response to the question about adequacy of provider services, $33 \%(n=6)$ replied that the services were adequate. In response as to what made the services adequate, subjects replied, "The doctor was proud of the fact that I didn't use [substances] during the pregnancy," and 
"The nurse practitioner listened to my fears regarding the baby's health.". Of the 18 women interviewed, $83 \%(\mathrm{n}=15)$ were satisfied with their provider care and $17 \%(\mathrm{n}=3)$ were not satisfied with their provider's care: "The doctor provided excellent medical care during pregnancy, however the doctor was not aware of my drug use. The doctor found out postpartum that I had a positive toxicology screen; the doctor was looking like he was in shock when he found out.".

In terms of the nurses that provided labor and delivery care and postpartum care, the following statements were made, "The nurses gave support during labor and were unaware of my being in recovery," and "After the results of my toxicology screen were positive, the nurses didn't allow me to be alone with my daughter and I had to visit her in the nursery.".

\section{Discussion}

This exploratory study examined the perceptions of pregnant and parenting substance abusing women regarding program support, social support, and provider support for an outpatient substance abuse rehabilitation program. The Social Stress Model of Substance Abuse (Rhodes \& Jason, 1990) was the conceptual model that incorporated all of these aspects and was utilized in this study.

In terms of program support, overall findings related to the subject's ability to maintain abstinence indicated that the educational classes, the coping mechanisms used to deal with stress, and the program staff most often assisted the women in the maintenance of their abstinence. In addition, the support and relationships developed with other participants in the program were helpful in maintaining abstinence. The ability to work together for a common goal with others sharing similar experiences, without being judged, was referred to as a strong social support, described by the participants as a "sisterhood" within the program. The findings of this study related to program support suggest that an educational component, including the risks and possible side effects of drug use, is a necessary requirement in treatment programs. Subjects 
expressed that the increased knowledge assisted them in maintaining their abstinence. Also, the ability of the clients in treatment to be given the opportunity to communicate with other participants is important. The inclusion of stress management techniques and strategies for coping with stress was also seen as helpful. Adaptation theories of drug abuse predict that an individual attempting to decrease or eliminate drug use will be at risk for drug use as a coping mechanism unless other coping strategies are available or can be developed (Chaney \& Rozelle, 1985). A team approach to treatment was effective, which enabled clients to obtain skills and assistance from various staff members with different experiences.

In reviewing the aspect of social support, the results showed that the majority of the women relied most heavily upon their parents. Other members of the support network were other family members, counselors, and sponsors. Social support, separate from the program or providers, was often not adequate. The results of this study suggest that family therapy and involvement of family members in the treatment component can have an impact on the maintenance of abstinence from substance abuse. If families are educated regarding the concept of drug addiction as a disease process, they may be more supportive to the recovering substance abuser.

The results also showed that almost half of the women reported that their provider was a source of support for them. Tarkka \& Paunonen (1996) found that women in a drug rehabilitation program indicated that the health care providers and the perinatal educators were perceived as providing some basic social support while caring for and treating chemically dependent women. Although about half of the women reported their providers as supportive in this study, the majority stated that the support was not adequate. Providers focused only on the medical care and did not extend the relationship to include substance abuse issues. As a result, issues of the women's substance use were not discussed as part of their prenatal care. In addition, the majority 
of the women reported not receiving any information regarding drug use and pregnancy. This study suggests that a substance abuse assessment should be completed for all patients as an integral part of prenatal care. In addition, subsequent assessments for substance abuse should be done throughout pregnancy. Included in the assessment should be an explanation of the risks and possible side effects resulting from substance use and pregnancy. Early assessment and interventions would also assist in reducing the risk of complications from substance abuse in pregnancy.

According to the Social Stress Model of Substance Abuse (Rhodes \& Jason, 1990), the utilization of appropriate coping mechanisms will lessen the chances of using drugs to cope with stress. The fact that the women reported relying upon their parents, their counselors, and other women in the program, suggests that social support from others is important in assisting with abstinence. The Social Stress Model of Substance Abuse defines one of the stress modifier categories as resources within the community, suggesting that individuals living in communities without appropriate resources are at a greater risk for drug use. The use of community resources as a drug use deterrent was supported since women listed resources as being effective in assisting them to maintain their abstinence. Some of the community resources reported by the women were medical services, dental services, the Women, Infant, and Children (WIC) program, social service programs, and housing assistance.

The study was limited by the sample size and the instrument utilized. The small convenience sample of 20 women precludes generalizing the results to the rest of the population. Many of the women were court mandated to be in this treatment program and may not represent the viewpoint of the population as a whole. Another limitation was the new instrument which was developed by the researchers and had no established reliability. 


\section{Implications for Clinical Practice}

Several implications for advanced nursing practice and other providers were suggested by this study. Nurse practitioners and physicians need to discuss the risks of substance abuse and pregnancy with their clients. Providers can complete a substance abuse assessment on all clients periodically throughout their prenatal care. It is also important to recognize substance abusing women in order for the women to receive the necessary assistance. Only $8 \%$ of the women reported receiving written material regarding drug use during pregnancy. Providers' projection of a non-judgemental attitude will facilitate building a positive patient-provider relationship. This relationship should assist the patient to feel comfortable in approaching the provider, as well as establishing trust in him/her. The provider can also reinforce positive behaviors during pregnancy, give treatment referrals, and provide a more holistic approach to patient care. Advanced practice nurses can provide effective treatment for substance abusing women if the focus is on holistic care and advocacy for patients.

\section{Recommendations}

This study should be replicated using a larger sample size with multiple outpatient drug treatment sites in order for the results to be more generalizable. Another recommendation would be to utilize a well documented instrument in the research with proven reliability. Future research could include a longitudinal design to determine if the women's social support network and abstinence continued after the women graduated from the drug rehabilitation program. 
Reference List

Blume, S. (1992) . Alcohol and other drug problems in women. In J. II. Lowinson, P. Ruiz, R. B. Millman, \& J. G. Langrod (Vol. Ed. ), Substance abuse: A comprehensive textbook (2nd ed. , pp. 794-807). Baltimore: Williams \& Wilkins.

Caplan, G. \& Killilea, M. (1976) . Support systems and mutual help. New York: Grune \& Stratton.

Carten, A. (1996) . Mothers in recovery: Rebuilding families in the aftermath of addiction. Social Work 41, 214-223.

Center for Substance Abuse Treatment (1993) . Improving treatment for drug exposed infants (DHHS Publication NO SMA 93-200). Washington, DC: US Department of Health and Human Services, Public Health Service, Substance Abuse, and Mental Health Service Administration.

Chaney, E. F. \& Rozelle, D. K. (1985) . Coping in opiate addicts maintained on methadone. In S. Shiffman \& T. A. Wills (Ed. ), Coping and substance use. Orlando, FL: Academic Press.

Elk, R. , Mangus, L. , Rhoades, H. , Andres, R. , \& Grabowski, J. (1998) . Cessation of cocaine use during pregnancy: Effects of contingency management interventions on maintaining abstinence and complying with prenatal care. Addictive Behaviors, 23 , 57-64.

Finkelstein, N. (1994) . Treatment issues for alcohol-and-drug-dependent pregnant and parenting women. Health \& Social Work. 19 7-15.

Higgins, P. , Clough, D. , \& Wallerstedt, C. (1996) . Chemically dependent women's reactions to pregnancy. The Journal of Perinatal Education, 5 , 37-43. 
Jansson, L. , Gazaway, P. , Cullins, V. , Huggins, G. \& Folden, A. (1993). The center of addiction and pregnancy: Preliminary results of an intensive multidisciplinary program for polysubstance abusing women. In L. Harris (Ed) ., Problems of drug dependence, 1992 (Research Monograph 132). Rockville, MD: National Institute on Drug Abuse.

Kelley, S. J. (1998). Stress and coping behaviors of substance abusing mothers. Journal of the Societv of Pediatric Nurses, 3, 103-110.

Lindenberg, C. S. , Gendrop, S. C. , \& Reiskin, H. K. (1993) . Empirical evidence for the social stress model of substance abuse. Research in Nursing and Health. 16, 351-362.

Nardi, D. (1998) . Addiction recovery for low-income pregnant and parenting women: A process of becoming. Archives of Psychiatric Nursing, 2,81-89.

National Institute on Drug Abuse. (1995) . National pregnancy and health survey, 1992. NIDA Notes $10(1), 6-7$.

Rhodes, J. E. , \& Jason, L. A. (1990) . A social stress model of substance abuse. Joumal of Consulting and Clinical Psychology, 58, 1-7.

Svikis, D. , McCaul, M. , Feng, T. , Stuart, M. , Fox, M. , \& Stokes, E. (1998) . Drug dependence during pregnancy: Effects of an on-site support group. The Journal of Reproductive Medicine 43, 799-805.

Tarkka, M. T. \& Paunonen, M. (1996). Social support and its impact on mothers' experiences of childbirth. Journal of Advanced Nursing 23, (1), 70-75.

Wilkerson, N. N. (1997). Screening and assessment for substance abuse in the childbearing population. The Journal of Perinatal Education 6 11-20.

Worner, T. M. , \& Delgado, I. M. (1995). Women referred for treatment: Early versus traditional intervention. Substance Abuse 16, 39-47. 
Zlotnick, C. , Franchino, K. , St. Claire, N. , Cox, K. , \& St. John, M. (1996) . The impact of outpatient drug services on abstinence among pregnant and parenting women. Journal of Substance Abuse and Treatment. 13, 195-202. 
Table 1

Demographic Data $(\mathrm{N}=20)$

$\begin{array}{lllll}\text { Characteristic } & n & \text { Percent } & M & \text { Range }\end{array}$

Age in years

$30 \quad 19-37$

Ethnicity

$\begin{array}{lcr}\text { Hispanic } & 11 & 55 \% \\ \text { African American } & 2 & 10 \% \\ \text { Filipino } & 1 & 5 \% \\ \text { Caucasian } & 4 & 20 \% \\ \text { Vietnamese } & 1 & 5 \% \\ \text { American Indian } & 1 & 5 \%\end{array}$

Marital Status

$\begin{array}{lrr}\text { Single } & 14 & 70 \% \\ \text { Married } & 3 & 15 \% \\ \text { Divorced } & 3 & 15 \%\end{array}$

Number of Children

\section{$3.3 \quad 1-10$}

Number of Pregnancies

$4.9 \quad 1-14$

Education (highest year)

$10.8 \quad 7-13$

Employment

$\begin{array}{lcc}\text { Employed } & 1 & 5 \% \\ \text { Unemployed with } & & \\ \text { public assistance } & 19 & 95 \%\end{array}$


Table 2

Subjects' Substance Use

n

Percent

Drug of choice ( $\mathrm{N}=33$ responses)

LSD

PCP

Crack/Cocaine

Methamphetamines/Crank

Marijuana

Alcohol

Prescription

Poly drug users ( $\mathrm{N}=20$ participants)

Age of first drug use ( $N=20$ participants)

10-15

$16-20$

$21-26$

Entrance to program (N=20 participants)

Court mandated

12

4

3
1

$3 \%$

$12 \%$

$18 \%$

$34 \%$

$12 \%$

$15 \%$

$6 \%$

$45 \%$

$45 \%$

$40 \%$

$15 \%$

3

$60 \%$

$20 \%$

$15 \%$

$5 \%$ 
Loss of Custody ( $\mathrm{N}=20$ participants)

Yes

No
12

8
$60 \%$

$40 \%$ 
Table 3

Categories of dealing with stresss

\begin{tabular}{|c|c|c|}
\hline Cognitive & Relaxation & Distraction/Avoidance \\
\hline Writing in journal & Meditation & Watch television \\
\hline Positive self talk & Calming self down & Don't let it bother self \\
\hline Making a list and & Allowing self to relax and & Walk away \\
\hline \multirow[t]{4}{*}{ prioritizing } & think & Go for a ride \\
\hline & Take a bath or deep & Don't argue \\
\hline & breaths & Shopping \\
\hline & & Keeping busy \\
\hline Emotional & Social Support & Spiritual \\
\hline Crying & Talking with family & Praying \\
\hline \multirow[t]{2}{*}{ Worrying } & Talking with counselor & Counting your blessings \\
\hline & Talking with a friend & \\
\hline Physical & Talking with others in program & \\
\hline Walking & Attend an AA/NA meeting & \\
\hline
\end{tabular}


Table 4

Subjects reporting supportive staff roles

n Percent

Supportive staff roles*

Counselor

Program manager

All staff

Parenting teacher
16

$62 \%$

3

6

1
$12 \%$

$23 \%$

$4 \%$

*Note: Based on 26 supportive staff roles as reported by subjects. 
Table 5

Perceptions of perinatal educators and providers

\begin{tabular}{lccc}
\hline & Supportive & Trustworthy & Adequate \\
\hline Perinatal educator $(n=14)$ & $50 \%$ & $50 \%$ & $64 \%$ \\
Physician/Nurse practitioner $(n=18)$ & $45 \%$ & $91 \%$ & $33 \%$ \\
\hline
\end{tabular}

